Check for updates

Cite this: RSC Adv., 2018, 8, 28131

Received 16th June 2018

Accepted 17th July 2018

DOI: 10.1039/c8ra05167d

rsc.li/rsc-advances

\title{
Enhanced electrocatalytic performance of nickel diselenide grown on graphene toward the reduction of triiodide redox couples $\uparrow$
}

\begin{abstract}
Xiao Zhang, (D) Haijun Zhang, (D) Xingyu Wang and Xiaomeng Zhou*
The promising activity of nickel diselenide $\left(\mathrm{NiSe}_{2}\right)$ towards electrocatalysis has made it especially attractive in energy conversion fields. However, $\mathrm{NiSe}_{2}$ with high electrocatalytic performance always requires complicated fabrication or expensive conductive polymers, resulting in the scale-up still being challenging. Herein, we introduce a simple and cost-effective synthesis of $\mathrm{NiSe}_{2}$ dispersed on the surface of graphene ( $\mathrm{NiSe}_{2} / \mathrm{RGO} \mathrm{NPs}$ ). $\mathrm{NiSe}_{2} / \mathrm{RGO}$ NPs exhibited enhanced electrocatalytic performance and long-term stability for the reduction reaction of triiodide redox couples in dye-sensitized solar cells (DSSCs). Leveraging the advantageous features, the DSSC fabricated with $\mathrm{NiSe}_{2} / \mathrm{RGO} N P S$ as CE had a smaller charge-transfer resistance $\left(R_{\mathrm{ct}}\right)$ value and higher short-circuit current density and fill factor than naked $\mathrm{NiSe}_{2}$ NPs. Additionally, NiSe 2 /RGO NPs achieved a PCE of $7.76 \%$, higher than that of pure $\mathrm{NiSe}_{2}(6.51 \%)$ and even exceeding that of Pt (7.56\%). These prominent features demonstrated that the $\mathrm{NiSe}_{2} / \mathrm{RGO}$ NPs in this work are a promising cheap and efficient electrocatalyst to replace state-of-theart Pt.
\end{abstract}

\section{Introduction}

Increasingly serious environmental problems and energy crises have resulted in an urgent need for renewable clean energy to replace the diminishing fossil fuel. ${ }^{1-4}$ Dye-sensitized solar cells (DSSCs) are a promising alternative to the conventional inorganic silicon-based solar cell owing to their environmental friendliness, facile fabrication, low cost and high power conversion efficiency (PCE)..$^{5-7}$ The cost and performance of a DSSC is strongly influenced by its counter electrode (CE) materials. Traditionally, noble metal platinum $(\mathrm{Pt})$ coated on an FTO substrate has proven to be a preferable CE for DSSCs because of its excellent catalytic activity and high conductivity. ${ }^{8-10}$ Nevertheless, its drawbacks of high cost (US\$50/gram), low natural abundance in earth $(0.0037 \mathrm{ppm})$, and being easily decomposed to harmful $\mathrm{PtI}_{4}$ and $\mathrm{H}_{2} \mathrm{PtI}_{6}$ byproducts, make it unsuitable in terms of sustainable development. ${ }^{11,12}$ Given the above considerations, it is of great importance and desirability to develop a low-cost, earth-abundant and anticorrosive Pt-free electrocatalyst with high electrical conductivity and excellent catalytic activity simultaneously for the reduction of $\mathrm{I}_{3} \cdot{ }^{13-17}$

Given the above considerations, earth-abundant transitional metal dichalcogenides ( $\mathrm{MX}_{2}, \mathrm{M}=\mathrm{Fe}, \mathrm{Co}$, or $\mathrm{Ni}$ and $\mathrm{X}=\mathrm{S}$ or $\mathrm{Se}$ ) have been applied as $\mathrm{CE}$ electrocatalysts and found to be

Center for Aircraft Fire and Emergency, Civil Aviation University of China, Tianjin 300300, P. R. China. E-mail: zhouxm@nankai.edu.cn

$\dagger$ Electronic supplementary information (ESI) available. See DOI: $10.1039 / \mathrm{c} 8 \mathrm{ra05167d}$ competitive Pt alternatives, benefiting from their intrinsic metallic properties. ${ }^{15,18-21}$ Especially, nickel diselenide $\left(\mathrm{NiSe}_{2}\right)$ is a Pauli paramagnetic metal with a resistivity below $10^{-3} \Omega \mathrm{cm}$, and its metallicity makes it use in electrocatalyst applications appealing. ${ }^{22-24}$ Although considerable advances have been made to $\mathrm{NiSe}_{2}$ electrocatalysts, the lack of ability to engineer $\mathrm{NiSe}_{2}$ nanostructures frequently leads to agglomeration of $\mathrm{NiSe}_{2}$ during high-temperature synthesis and electrocatalytic reaction processes for the isotropic crystal structures, which leads to a decrease in surface area, electrical conductivity and the number of catalytically active sites. Although some modified preparation methods and conductive polymers have been employed to fabricate robust and stable $\mathrm{NiSe}_{2}$ electrocatalysts with enhanced electrocatalytic performance, complicated and expensive electrode fabrication procedures mean that scale-up is still challenging. In this regard, the most practical fabrication is nothing more than using facile one-step solvothermal methods to grow nanostructured $\mathrm{NiSe}_{2}$ anchored on selfstanding conductive carbon supports (graphene, carbon cloth, carbon fiber paper). ${ }^{25,26}$ The assembly of pristine $\mathrm{NiSe}_{2}$ onto suitable carbon supports improves the dispersed distribution of $\mathrm{NiSe}_{2}$ nanostructures, maintains the exposed surface and enhances the application efficiency of active sites.

Following this line of thought, in the present work, we devoted our efforts to fabricating $\mathrm{NiSe}_{2}$ nanoparticles grown on reduced graphene oxide (RGO) through a facile one-step solvothermal method. The as-obtained $\mathrm{NiSe}_{2}$ nanoparticles dispersed on the surface of RGO ( $\mathrm{NiSe}_{2} / \mathrm{RGO} \mathrm{NPs}$ ) exhibited more efficient active sites and charge-transfer pathways 
compared with pure $\mathrm{NiSe}_{2}$ nanoparticles ( $\mathrm{NiSe}_{2} \mathrm{NPs}$ ). Taking advantage of this combination, the DSSC fabricated with the $\mathrm{NiSe}_{2} / \mathrm{RGO}$ NPs as the CE exhibited a smaller charge-transfer resistance $\left(R_{\mathrm{ct}}\right)$ value and higher short-circuit current density $\left(J_{\mathrm{SC}}\right)$ than those of pure $\mathrm{NiSe}_{2}$ NPs. Additionally, $\mathrm{NiSe}_{2} / \mathrm{RGO}$ NPs achieved a PCE of $7.76 \%$, higher than that of pure $\mathrm{NiSe}_{2}(6.51 \%)$ and even exceeding that of $\mathrm{Pt}(7.56 \%)$. These prominent features demonstrated that $\mathrm{NiSe}_{2} / \mathrm{RGO}$ NPs are one of the most ideal electroactive materials to replace expensive Pt material for DSSC.

\section{Experimental}

\subsection{Synthesis of graphene oxide}

Before synthesizing the $\mathrm{NiSe}_{2} / \mathrm{RGO} \mathrm{NPs}$ and $\mathrm{NiSe}_{2} \mathrm{NPs}$, graphene oxide (GO) was firstly prepared by a modified Hummers' method; detailed information is shown in the ESI. $\dagger^{27}$ The concentration of GO aqueous solution was about $10 \mathrm{mg} \mathrm{mL}^{-1}$.

\subsection{Synthesis of $\mathrm{NiSe}_{2} / \mathrm{RGO}_{\mathrm{NPs}}$ and $\mathrm{NiSe}_{2} \mathrm{NPs}$}

$\mathrm{NiSe}_{2} /$ RGO NPs were prepared by a simple solvothermal method. A typical preparation procedure was as follows: $3 \mathrm{mmol}$ of $\mathrm{Ni}\left(\mathrm{CH}_{3} \mathrm{COO}\right)_{2} \cdot 4 \mathrm{H}_{2} \mathrm{O}$ was dissolved in $35 \mathrm{~mL}$ of distilled water. Then $5 \mathrm{~mL}$ of GO aqueous solution was added under continuous stirring for 1 hour to form a uniform dispersion. After this, $6 \mathrm{mmol}$ of Se powder was placed into the mixture. Subsequently, $5 \mathrm{~mL}$ of hydrazine hydrate was added dropwise to reduce the Se and GO. The resulting solution was put into a Teflon-lined autoclave of $50 \mathrm{~mL}$ capacity and heated at $150{ }^{\circ} \mathrm{C}$ for $15 \mathrm{~h}$. Then, the autoclave was allowed to cool to room temperature naturally. The product was washed with water and absolute ethanol to remove impurities, and then dried at $60{ }^{\circ} \mathrm{C}$. Similarly, $\mathrm{NiSe}_{2}$ NPs were synthesized by the same method without graphene.

\subsection{Characterization of obtained samples}

The crystallinity and composition of the samples were characterized by X-ray diffraction (XRD, D/max-2500, JAPAN SCIENCE) with $\mathrm{Cu} \mathrm{K} \alpha$ radiation $(\lambda=1.54056 \AA)$. The chemical states and bonding characteristics of the samples were determined by Raman spectra (Renishaw inVia spectrometer, $514.5 \mathrm{~nm}$ laser) and X-ray photoelectron spectroscopy (XPS) analysis (PHI 5000 VersaProbe). The morphology of the samples was studied by field-emission scanning electron microscopy (FE-SEM, Nanosem 430, FEI). More detailed insight into the microstructure of the sample was obtained by high-resolution transmission electron microscopy (TEM, Tecnai G2 F20, operating at $200 \mathrm{kV}$, FEI).

\subsection{Fabrication of DSSCs}

The CE materials slurry was made in ethanol by mixing $0.1 \mathrm{~g}$ of CE materials powder with $0.025 \mathrm{~g}$ of PEG20000, which was used as the dispersant as well as the binder, and stirred continuously. A film was then made by using a doctor-blade to wipe the $\mathrm{CE}$ materials slurry on FTO conductive glass (LOF, TEC-15, $15 \mathrm{~W}$ per square). After the film was steady, the conductive glass with film was heated at $400{ }^{\circ} \mathrm{C}$ for $1 \mathrm{~h}$ under the protection of argon, and the counter electrode was obtained.

A commercial $\mathrm{TiO}_{2}$ sol (Solaronix, Ti-Nanoxide T/SP) was used to prepare the $\mathrm{TiO}_{2}$ film on FTO also through the doctorblade method, and the film was soaked in an N719 dye solution (in ethanol) for $24 \mathrm{~h}$ to obtain dye-sensitized $\mathrm{TiO}_{2}$ electrodes. DSSCs were assembled by injecting the electrolyte into the aperture between the dye-sensitized $\mathrm{TiO}_{2}$ electrode and the counter electrode. The liquid electrolyte was composed of $0.05 \mathrm{M} \mathrm{I}_{2}, 0.1 \mathrm{M}$ LiI, 0.6 M 1, 2-dimethyl-3-propylimidazolium iodide (DMPII), and 0.5 M 4-tert-butyl pyridine with acetonitrile as the solvent. Surlyn 1702 was used as the spacer between the two electrodes. The two electrodes were clipped together and solid paraffin was used as the sealant to prevent the electrolyte solution from leaking. The effective cell area was 0.25 $\mathrm{cm}^{2}$. The standard sputtered Pt CE was purchased from Dalian Heptachroma Solar Tech Co., Ltd.

\subsection{Characterization of CEs and DSSCs}

All the electrochemical measurements were obtained using the Zahner IM6 electrochemical workstation. Photocurrent-voltage curves were obtained under simulated AM 1.5 illumination (100 $\mathrm{mW} \mathrm{cm}^{-2}$, Trusttech CHF-XM-500W) with a Keithley digital source meter (Keithley 2410, USA). Electrochemical impedance spectroscopy (EIS) analysis was conducted at zero bias potential and the impedance data covered a frequency range of $0.1 \mathrm{~Hz}$ to 1 MHz. The amplitude of the sinusoidal AC voltage signal was $5 \mathrm{mV}$. The analyses of the resulting impedance spectra were conducted using Zview 2.0 software. Tafel-polarization measurements were employed in a symmetrical dummy cell, which was used in the EIS experiments. The electrolyte was as the same of the electrolyte of DSSC. The scan rate was $20 \mathrm{mV}$ $\mathrm{s}^{-1}$, and the voltage range was -1.0 to $1.0 \mathrm{~V}$. Cyclic voltammetry (CV) was recorded using a three-electrode system on the electrochemical workstation. Pt was used as the counter electrode and $\mathrm{Ag} / \mathrm{AgCl}$ was used as the reference electrode. A solution of 10.0 $\mathrm{mM} \mathrm{LiI,} 1.0 \mathrm{mM} \mathrm{I}_{2}$, and $0.1 \mathrm{M} \mathrm{LiClO}_{4}$ in acetonitrile served as the electrolyte.

\section{Results and discussion}

XRD and Raman spectroscopy were employed to determine the crystalline-phase structures and purity of the as-prepared $\mathrm{NiSe}_{2} /$ RGO, $\mathrm{NiSe}_{2}$ and GO samples. Fig. 1a displays the XRD patterns of $\mathrm{NiSe}_{2} / \mathrm{RGO}$ (red line) and $\mathrm{NiSe}_{2}$ (green line) for reference. The XRD patterns revealed that all diffraction peaks of both $\mathrm{NiSe}_{2} /$ RGO and $\mathrm{NiSe}_{2}$ samples are sharp, indicative of the good crystallization of the as-prepared samples. The strongest peak of $\mathrm{NiSe}_{2} / \mathrm{RGO}$ and $\mathrm{NiSe}_{2}$ samples was found at position $33.41^{\circ}$, corresponding to the (210) plane. Major diffraction peaks observed at diffraction angles are in a good agreement with the cubic $\mathrm{NiSe}_{2}$ (JCPDS card, no. 88-1711) and a previous report. ${ }^{28}$ It is worth noting that no other impurity phases were detected, confirming the very high purity of the obtained $\mathrm{NiSe}_{2} / \mathrm{RGO}$ and $\mathrm{NiSe}_{2}$ samples. Besides, the obtained $\mathrm{NiSe}_{2}$ possesses a pyrite structure (Fig. 1b) with the octahedral arrangement of the 


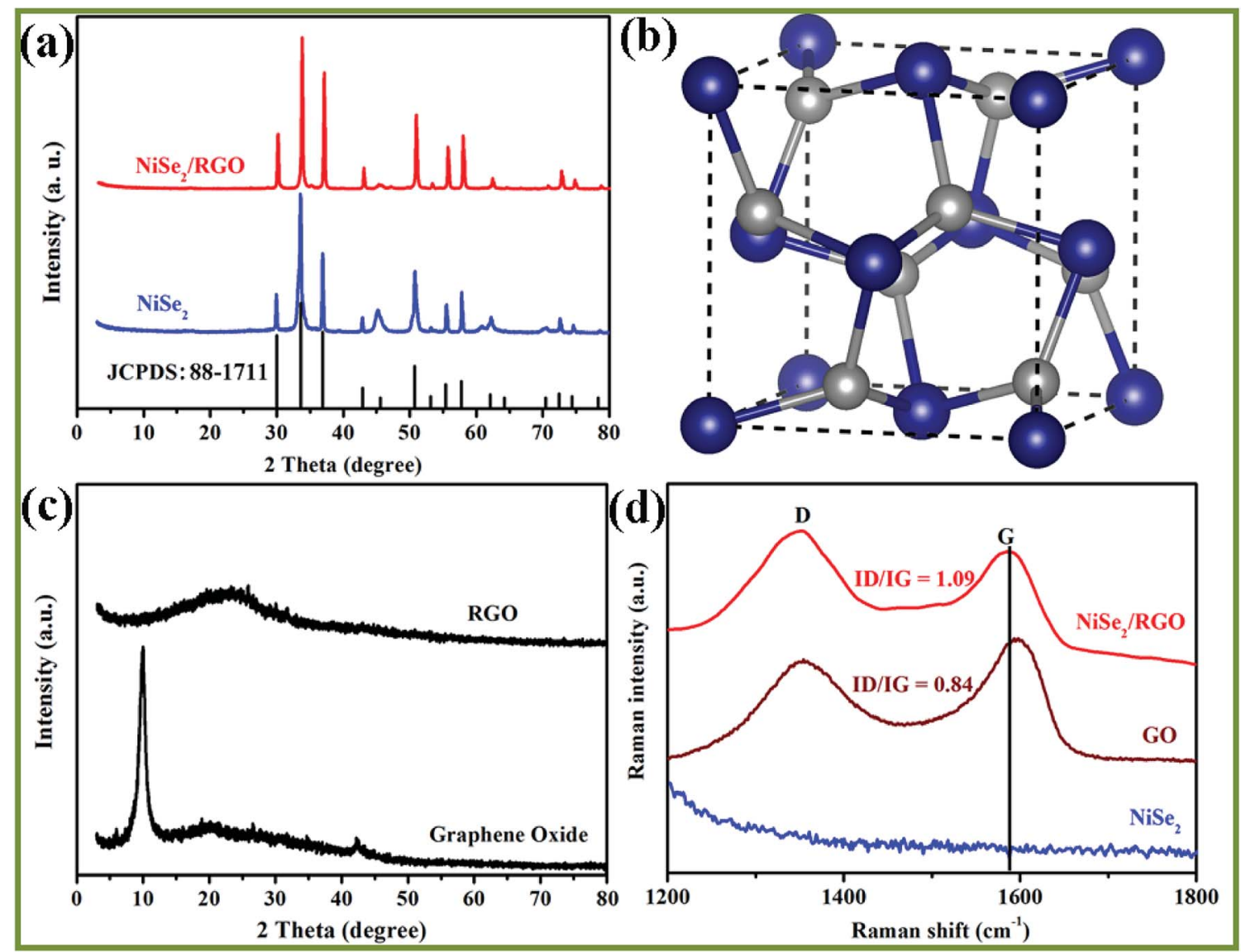

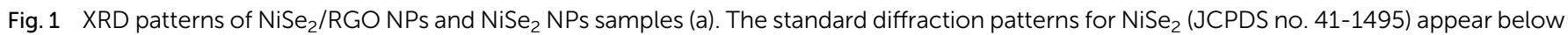
the pattern. Crystal structure of cubic pyrite $\mathrm{NiSe}_{2}$ (Ni blue, Se grey) (b). XRD patterns of GO and RGO (c). Raman spectra of NiSe $2 / R G O ~ N P s, ~ G O$ and $\mathrm{NiSe}_{2}$ NPs (d).

adjacent Se atoms units between two Ni atoms. ${ }^{22,29}$ As seen in Fig. 1c, GO shows a significant (002) peak at $10.02^{\circ}$, while the main peak of RGO shifted to a larger angle at $23.6^{\circ}$. In the Raman spectra (Fig. 1d), two characteristic peaks in accordance with the D and G bands of $\mathrm{NiSe}_{2} / \mathrm{RGO}$ and GO were clearly observed. Furthermore, the G band shifted to lower frequency with the increased $I_{\mathrm{D}} / I_{\mathrm{G}}$ ratio (1.09) in $\mathrm{NiSe}_{2} / \mathrm{RGO}$ compared with GO $\left(I_{\mathrm{D}} / I_{\mathrm{G}}\right.$ was 0.84$)$. The shifted Raman frequency and increased $I_{\mathrm{D}} / I_{\mathrm{G}}$ ratio further confirmed the reduction of GO and the presence of RGO in $\mathrm{NiSe}_{2} / \mathrm{RGO}^{30}$

The chemical states and surface composition of $\mathrm{NiSe}_{2} / \mathrm{RGO}$ were identified by XPS spectra (Fig. 2). In the high-resolution Ni 2p spectrum (Fig. 2a), six asymmetric peaks could be observed. Two peaks at 855.6 and $873.2 \mathrm{eV}$ correspond to $\mathrm{Ni} 2 \mathrm{p}_{3 / 2}$ and $\mathrm{Ni}$ $2 \mathrm{p}_{1 / 2}$, respectively. The peaks at 853.4 and $870.6 \mathrm{eV}$ are ascribed to $\mathrm{Ni}^{2+}$ ions, the peaks at 855.6 and $873.2 \mathrm{eV}$ are ascribed to $\mathrm{Ni}^{3+}$ ions in the surface oxide phase, while two satellite peaks at 861.8 and $880.8 \mathrm{eV}$ are ascribed to the $\mathrm{Ni}^{2+}$ oxidation state. ${ }^{24,31}$ Deconvoluting the Se peak, the peaks with binding energies of

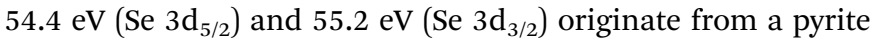
$\mathrm{NiSe}_{2}$ compound, while another peak with binding energy of $58.4 \mathrm{eV}$ corresponds to the surface oxidation of Se species. ${ }^{25,31}$ XRD, Raman and XPS characterizations confirmed that $\mathrm{NiSe}_{2} /$ RGO and $\mathrm{NiSe}_{2}$ were obtained.
The microstructure and morphology of $\mathrm{NiSe}_{2} / \mathrm{RGO}$ NPs was investigated by scanning electron microscopy (SEM) and transmission electron microscopy (TEM). The SEM image in Fig. 3a shows that the $\mathrm{NiSe}_{2} / \mathrm{RGO}$ samples are nano-sized particles and tend to disperse on the surface of graphene nanosheets. The low magnification TEM image (Fig. 3b) further implies that the as-obtained $\mathrm{NiSe}_{2} / \mathrm{RGO}$ samples were dispersed on the graphene, and the grey ultrathin nanosheets in the range of vision are graphene. The nanoparticle diameter of the $\mathrm{NiSe}_{2} /$ RGO samples is in the range of 35 to $50 \mathrm{~nm}$, determined by magnified TEM image (Fig. 3c). From the HRTEM image (Fig. 3d), the distinct lattice spacing of the $\mathrm{NiSe}_{2} / \mathrm{RGO} \mathrm{NPs} \mathrm{nm}$ can be observed. In contrast with the serious agglomeration of pure $\mathrm{NiSe}_{2}$ NPs (Fig. S1 $\dagger$ ), the dispersed distribution of $\mathrm{NiSe}_{2} /$ RGO NPs with the addition of graphene could increase the amount of efficient catalytic active sites, improve the chargetransfer ability and enhance the catalytic activity. SEM and TEM measurements of graphene are shown in Fig. S2. $\dagger$

To investigate the charge-transfer ability and catalytic activity of $\mathrm{NiSe}_{2} / \mathrm{RGO} \mathrm{NPs}$ and $\mathrm{NiSe}_{2}$ NPs samples as CEs of DSSCs, Nyquist plots of the electrochemical impedance spectroscopy (EIS) for CEs were obtained using symmetric dummy cells fabricated with a sandwich-like structure (CE/electrolyte/ CE). The Nyquist plots are shown in Fig. 4 and the relevant 

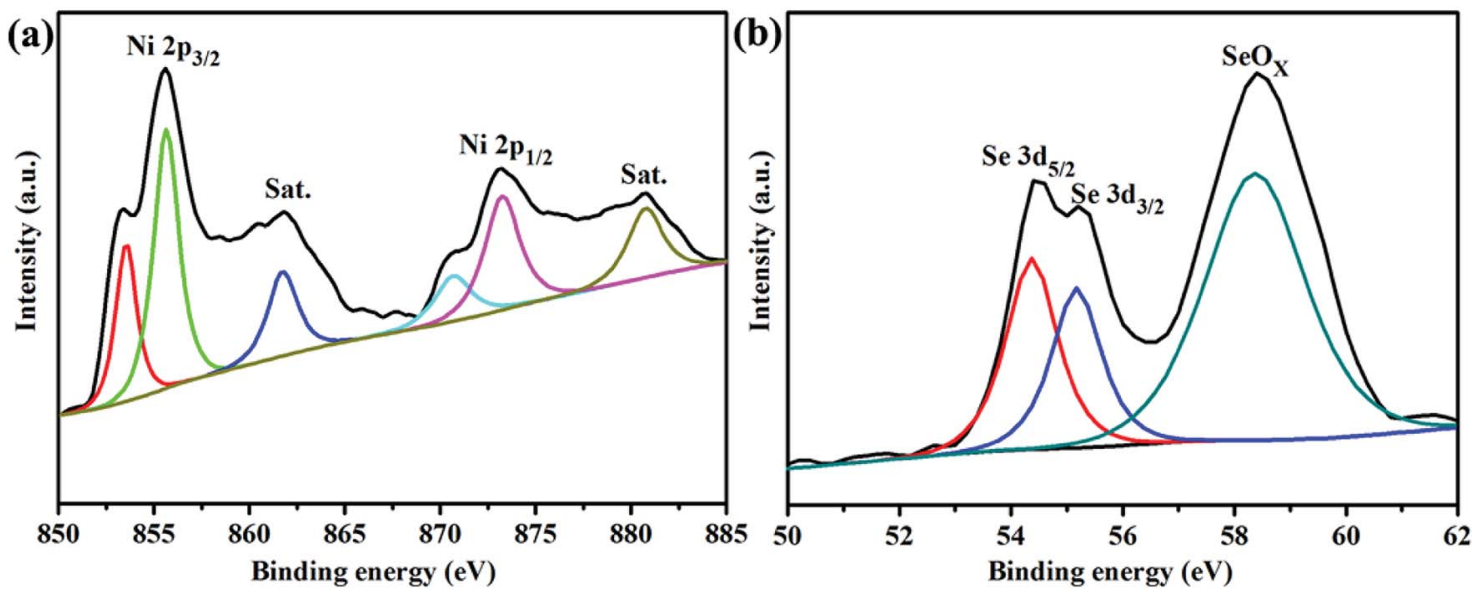

Fig. 2 XPS analysis of the Ni $2 p$ and Se $3 d$ spectra of $\mathrm{NiSe}_{2} / \mathrm{RGO}$ NPs.

equivalent circuit diagram is shown as an inset; the corresponding parameters fitted by Z-view software are listed in Table 1. The intercept of the real axis of high frequency in Nyquist plots is series resistance $\left(R_{\mathrm{S}}\right)$, and the diameter of the high-frequency (left) semicircle is charge transfer resistance $\left(R_{\mathrm{ct}}\right){ }^{32}$ The $R_{\mathrm{S}}$ value of $\mathrm{NiSe}_{2} \mathrm{NPs} \mathrm{CE}$ is $14.99 \Omega \mathrm{cm}^{-2}$, and after being combined with graphene the $R_{\mathrm{S}}$ value of $\mathrm{NiSe}_{2} / \mathrm{RGO}$ NPs CE is $14.26 \Omega \mathrm{cm}^{-2}$, slightly lower than that of Pt CE $\left(R_{\mathrm{S}}=14.53\right.$ $\left.\Omega \mathrm{cm}^{-2}\right) . R_{\mathrm{ct}}$ is the other important parameter obtained in Nyquist plots, negatively correlating with the charge-transfer ability and catalytic activity of the CEs. ${ }^{16,33}$ Simultaneously, from the parameters in Table 1, the $R_{\mathrm{ct}}$ value of $\mathrm{NiSe}_{2} / \mathrm{RGO}$ NPs $\mathrm{CE}\left(R_{\mathrm{ct}}=1.52 \Omega \mathrm{cm}^{-2}\right)$ is also lower than that of $\mathrm{NiSe}_{2} \mathrm{NPs} \mathrm{CE}$ $\left(R_{\mathrm{ct}}=3.82 \Omega \mathrm{cm}^{-2}\right)$, and even inferior to that of Pt CE $\left(R_{\mathrm{ct}}=1.72\right.$ $\Omega \mathrm{cm}^{-2}$ ), indicative of its supreme electrocatalytic activity for triiodide reduction. ${ }^{19,34}$ The integration of low $R_{\mathrm{ct}}$ and $R_{\mathrm{S}}$ of $\mathrm{NiSe}_{2} / \mathrm{RGO}$ NPs CE can efficiently lower the charge transfer resistance and facilitate the transfer of electron, thus contributing to the improvement of the electrocatalytic performance of DSSCs. $^{35}$

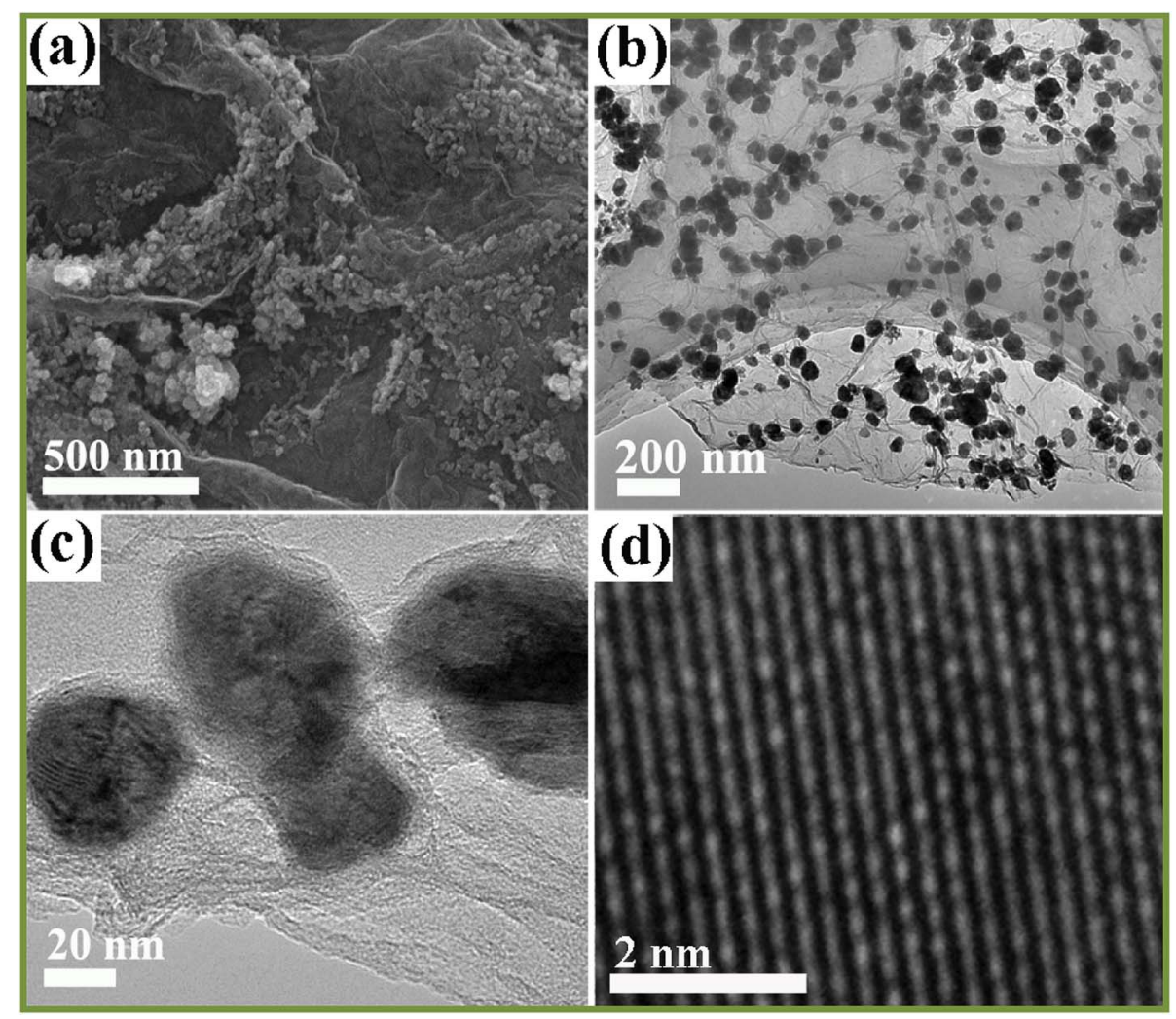

Fig. 3 SEM (a), TEM (b and c) and HRTEM (d) images of $\mathrm{NiSe}_{2} / \mathrm{RGO}$ NPs. 


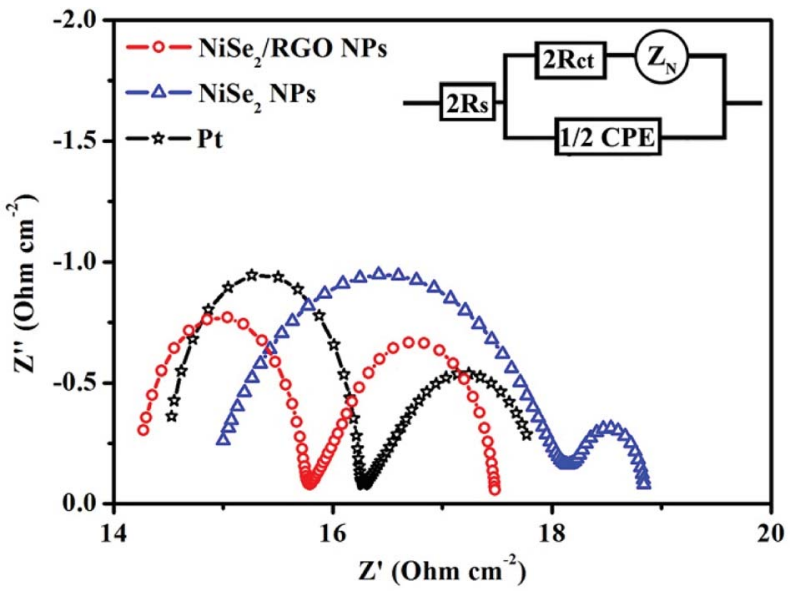

Fig. 4 Nyquist plots for dummy cells fabricated with $\mathrm{NiSe}_{2} / \mathrm{RGO}$ NPs, $\mathrm{NiSe}_{2}$ NPs and Pt CEs. The inset gives the equivalent circuit.

Tafel polarization measurement is an effective technique for examining the charge-transfer kinetics of CEs. Symmetric cells with the sandwich-type configuration of CEs are fabricated using the same method as that used for the EIS. The polarization zone of the Tafel polarization curve (Fig. 5) corresponds to the high-frequency region of Nyquist plots, and the diffusion zone relates to the low-frequency region. ${ }^{36,37}$ In the Tafel polarization curve, the limiting diffusion current density $\left(J_{\lim }\right.$, the intersection of the anodic branch with the $y$ axis) and the exchange current density $\left(J_{0}\right.$, the slope for the anodic or cathodic branch) are closely correlated with the diffusion ability of $\mathrm{I}_{3}{ }^{-}$at the electrode/electrolyte interface and the electrocatalytic activity of the CEs, respectively ${ }^{38,39} \mathrm{~A}$ higher $J_{\mathrm{lim}}$ reveals a larger ionic diffusion coefficient between the two electrodes based on eqn (1):

$$
D=l J_{\lim } / 2 n F C
$$

where $D$ is the diffusion coefficient, $l$ is the distance between the two electrodes, $n(n=2)$ is the total number of electrons involved in the reduction at the electrolyte-CE interfaces, $F$ is the Faraday constant, and $C$ is the $\mathrm{I}_{3}{ }^{-}$concentration. The $J_{\mathrm{lim}}$ value of the $\mathrm{NiSe}_{2} / \mathrm{RGO} \mathrm{NPs} \mathrm{CE}\left(1.95 \log \left(\mathrm{mA} \mathrm{cm}^{-2}\right)\right)$ is higher than that of the NiSe ${ }_{2}$ NPs CE $\left(1.67 \log \left(\mathrm{mA} \mathrm{cm}^{-2}\right)\right)$, and slightly exceeds that of the Pt CE $\left(1.83 \log \left(\mathrm{mA} \mathrm{cm}^{-2}\right)\right)$. On the other hand, a higher $J_{0}$ indicates better catalytic activity for $\mathrm{I}_{3}^{-}$ reduction, and there is also a positive correlation between $J_{0}$ and $R_{\mathrm{ct}}$ based on eqn (2). ${ }^{40}$

$$
J_{0}=R T / n F R_{\mathrm{ct}}
$$

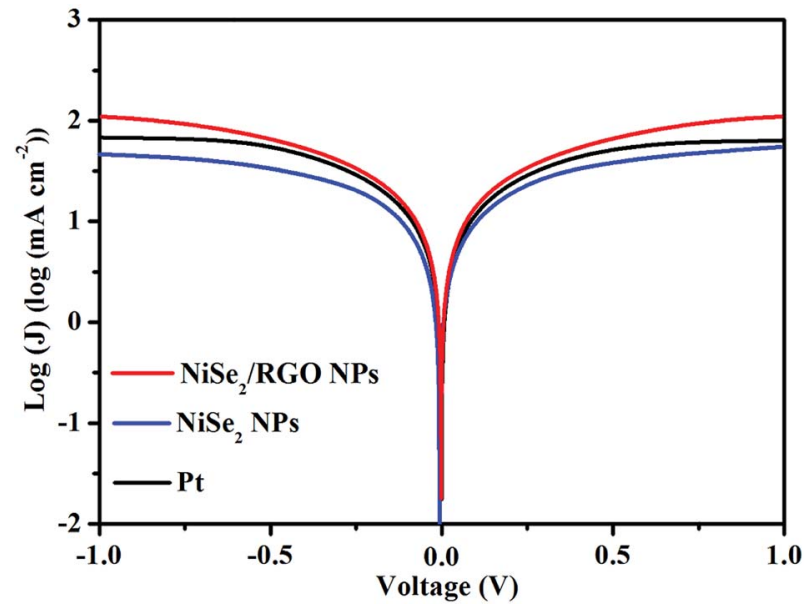

Fig. 5 Tafel polarization curves for dummy cells fabricated with $\mathrm{NiSe}_{2} /$ RGO NPs, $\mathrm{NiSe}_{2}$ NPs and Pt CEs between 1.0 and $-1.0 \mathrm{~V}$.

where $R$ is the gas constant, $T$ is the temperature and $R_{\mathrm{ct}}$ is the charge transfer resistance. Owing to the presence of graphene, $\mathrm{NiSe}_{2} / \mathrm{RGO}$ NPs CE exhibited higher $J_{\text {lim }}$ and $J_{0}$ values than $\mathrm{NiSe}_{2}$ NPs CE, which are in good agreement with the results of the EIS.

In order to further study the reaction kinetics of $\mathrm{NiSe}_{2} / \mathrm{RGO}$ NPs, $\mathrm{NiSe}_{2}$ NPs and Pt CEs for the reduction of triiodide, cyclic voltammetry (CV) was performed with a three-electrode system at a scan rate of $25 \mathrm{mV} \mathrm{s}^{-1}$. As presented in Fig. 6, two typical pairs of oxidation-reduction peaks can be clearly seen in each CV curve, indicating the same electrocatalytic mechanism toward triiodide reduction. ${ }^{12,41}$ From low potential to high

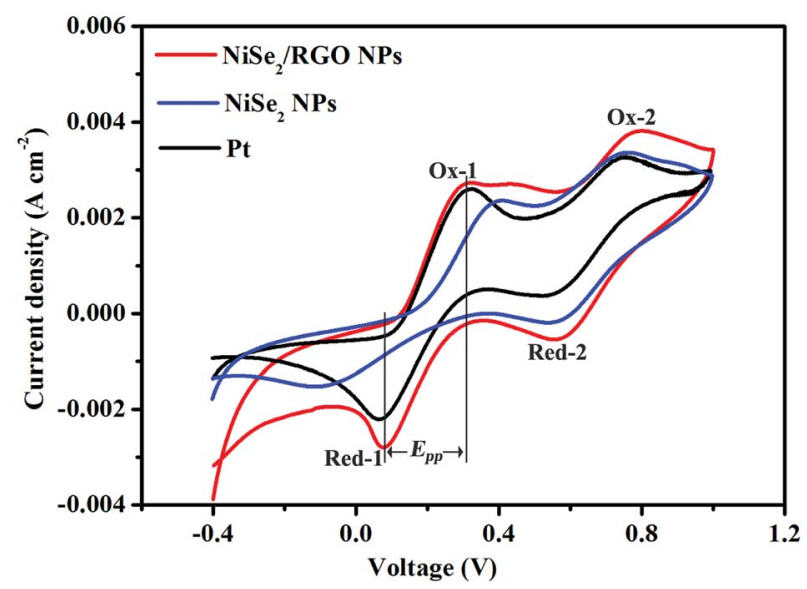

Fig. 6 Cyclic voltammograms of the $\mathrm{NiSe}_{2} / \mathrm{RGO} \mathrm{NPs}, \mathrm{NiSe}_{2} \mathrm{NPs}$ and Pt CEs at a scan rate of $25 \mathrm{mV} \mathrm{s}^{-1}$.

Table 1 The corresponding values of series resistance $\left(R_{\mathrm{S}}\right)$, charge-transfer resistance $\left(R_{\mathrm{ct}}\right)$, limiting diffusion current density $\left(J_{\text {lim }}\right)$, peak-to-peak separation $\left(E_{\mathrm{pp}}\right)$ and cathodic peak current density $\left(J_{\text {Red-1 }}\right)$

\begin{tabular}{llllll}
\hline $\mathrm{CE}$ & $R_{\mathrm{S}}\left(\mathrm{Ohm} \mathrm{cm} \mathrm{c}^{-2}\right)$ & $R_{\mathrm{ct}}\left(\mathrm{Ohm} \mathrm{cm}^{-2}\right)$ & $J_{\text {lim }} \log \left(\mathrm{mA} \mathrm{cm}^{-2}\right)$ & $E_{\mathrm{pp}}(\mathrm{mV})$ & $J_{\mathrm{Red}-1}\left(\mathrm{~mA} \mathrm{~cm}{ }^{-2}\right)$ \\
\hline $\mathrm{NiSe}_{2} /$ RGO NPs & 14.26 & 1.52 & 1.95 & 232 & 2.80 \\
$\mathrm{NiSe}_{2}$ NPs & 14.99 & 3.28 & 1.67 & 499 & 261 \\
$\mathrm{Pt}$ & 14.53 & 1.72 & 1.83 & 261
\end{tabular}


potential, the reactions of four oxidation-reduction peaks can be ascribed to eqns (3)-(6):

$$
\begin{aligned}
& \text { Ox-1: } 3 \mathrm{I}^{-}-2 \mathrm{e}^{-}=\mathrm{I}_{3}^{-} \\
& \text {Ox-2: } 2 \mathrm{I}_{3}{ }^{-}-2 \mathrm{e}^{-}=3 \mathrm{I}_{2} \\
& \text { Red-1: } \mathrm{I}_{3}{ }^{-}+2 \mathrm{e}^{-}=3 \mathrm{I}^{-} \\
& \text {Red-2: } 3 \mathrm{I}_{2}+2 \mathrm{e}^{-}=2 \mathrm{I}_{3}{ }^{-}
\end{aligned}
$$

The peak-to-peak potential separation $\left(E_{\mathrm{pp}}\right)$ between Red-1 and Ox-1 and the peak current intensity of Red-1 $\left(J_{\text {Red-1 }}\right)$ are two important parameters for assessing the electrocatalytic activity of a CE (Table 1). In detail, the $E_{\mathrm{pp}}$ value is negatively correlated with the standard electrochemical rate constant and positively with overpotential loss, and $J_{\text {Red-1 }}$ is positively correlated with reaction velocity and electrocatalytic activity. ${ }^{\mathbf{1 0 4 2}}$ The $\mathrm{NiSe}_{2} /$ RGO NPs CE exhibited a lower $E_{\mathrm{pp}}$ value $(232 \mathrm{mV})$ and a higher $J_{\text {Red-1 }}$ value $\left(2.80 \mathrm{~mA} \mathrm{~cm}{ }^{-2}\right)$ than those of the $\mathrm{NiSe}_{2} \mathrm{NPs}$ $\mathrm{CE}\left(E_{\mathrm{pp}}=499 \mathrm{mV}, J_{\text {Red-1 }}=1.56 \mathrm{~mA} \mathrm{~cm}^{-2}\right)$, revealing the better intrinsic electrocatalytic activity of the $\mathrm{NiSe}_{2} / \mathrm{RGO}$ NPs CE as well as a synergistic catalytic effect between $\mathrm{NiSe}_{2}$ and graphene. In comparison with the Pt $\left(E_{\mathrm{pp}}=261 \mathrm{mV}, J_{\text {Red-1 }}=2.22\right.$ $\mathrm{mA} \mathrm{cm}{ }^{-2}$ ) CE, the $E_{\mathrm{pp}}$ and $J_{\text {Red-1 }}$ of $\mathrm{NiSe}_{2} / \mathrm{RGO}$ NPs CE are also better, signifying that the electrocatalytic activity of the $\mathrm{NiSe}_{2} /$ RGO NPs CE is even superior to that of the Pt CE. ${ }^{\mathbf{4 3 , 4 4}}$

Photocurrent density-voltage $(J-V)$ curves of the integrated DSSCs fabricated with $\mathrm{NiSe}_{2} / \mathrm{RGO}, \mathrm{NiSe}_{2}$ and Pt CEs were measured under irradiation at $100 \mathrm{~mW} \mathrm{~cm}^{-2}$. The detailed photovoltaic parameters, including the values of open-circuit voltage $\left(V_{\mathrm{OC}}\right)$, short-circuit photocurrent density $\left(J_{\mathrm{SC}}\right)$, fill factor (FF) and power conversion efficiency (PCE), are summarized in Table 2. As shown in Fig. 7, it is obvious that the $V_{\mathrm{OC}}$ values of the $\mathrm{NiSe}_{2} / \mathrm{RGO} \mathrm{NPs}, \mathrm{NiSe}_{2}$ NPs and Pt CEs are similar, owing to the same photoanode, dye and electrolyte. Remarkably, the DSSC based on $\mathrm{NiSe}_{2} /$ RGO NPs CE reached a higher PCE $(7.76 \%)$ compared to that of $\mathrm{NiSe}_{2}$ NPs CE (6.51\%), which is even higher than that of $\mathrm{Pt}(\mathrm{PCE}=7.56 \%)$. This improvement may be visually attributed to the higher $J_{\mathrm{SC}}$ value of the $\mathrm{NiSe}_{2} /$ RGO NPs CE (17.15 $\left.\mathrm{mA} \mathrm{cm}{ }^{-2}\right)$ than those of the $\mathrm{NiSe}_{2}$ NPs CE $\left(15.16 \mathrm{~mA} \mathrm{~cm}^{-2}\right)$ and Pt CE $\left(15.99 \mathrm{~mA} \mathrm{~cm}^{-2}\right)$. On one hand, the well-dispersion of $\mathrm{NiSe}_{2}$ nanoparticles on the surface of graphene increased the number of catalytic active sites of $\mathrm{NiSe}_{2}$ nanoparticles for redox couple and enhanced the $\mathrm{I}_{3}{ }^{-}$reduction. ${ }^{45}$ On the other hand, the high conductive graphene provided faster electron transfer paths and accelerated the

Table 2 The corresponding values of open-circuit voltage $\left(V_{O C}\right)$, short-circuit current $\left(\mathrm{J}_{\mathrm{SC}}\right)$, fill factor $(\mathrm{FF})$, and power conversion efficiency (PCE)

\begin{tabular}{lllll}
\hline $\mathrm{CE}$ & $V_{\mathrm{OC}}(\mathrm{mV})$ & $J_{\mathrm{SC}}\left(\mathrm{mA} \mathrm{cm}^{-2}\right)$ & $\mathrm{FF}$ & PCE $(\%)$ \\
\hline $\mathrm{NiSe}_{2} /$ RGO NPs & 755 & 17.15 & 0.60 & 7.76 \\
$\mathrm{NiSe}_{2}$ NPs & 740 & 15.16 & 0.58 & 6.51 \\
$\mathrm{Pt}$ & 770 & 15.99 & 0.61 & 7.51
\end{tabular}

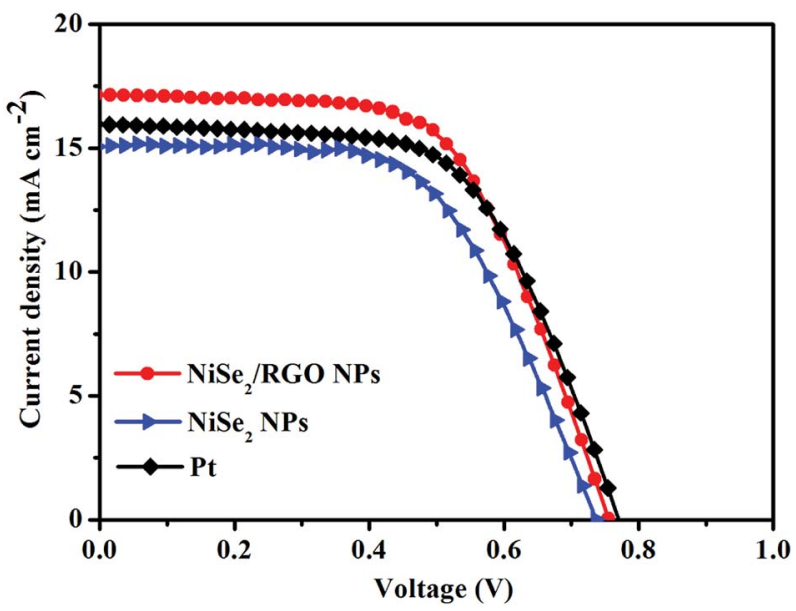

Fig. 7 Photocurrent density-voltage curves of DSSCs fabricated with $\mathrm{NiSe}_{2} / \mathrm{RGO} \mathrm{NPs}_{1} \mathrm{NiSe}_{2} \mathrm{NPs}$ and Pt CEs under simulated sunlight irradiation $\left(100 \mathrm{~mW} \mathrm{~cm}^{-2}\right)$.

transfer of photogenerated electrons collected from the external circuit to active sites, thus promoting the electrochemical reaction kinetics for the reduction of $\mathrm{I}_{3}{ }^{-}$to $\mathrm{I}^{-}$at $\mathrm{CE}$ and the regeneration of the dye at the photoanode. ${ }^{46}$ All these results demonstrated that dispersed $\mathrm{NiSe}_{2}$ nanoparticles on graphene yielded enhanced electrocatalytic activity and high conversion efficiency. The electrocatalytic performance characterizations, EIS, CV, Tafel polarization and $J-V$ curves of RGO are shown in Fig. S4. $\dagger$

To elucidate the relationship between the peak current densities (Ox-1 and Red-1) and the scanning rates, cyclic voltammetry (CV) measurements of the $\mathrm{NiSe}_{2} / \mathrm{RGO}$ NPs and $\mathrm{NiSe}_{2}$ NPs electrodes were conducted at different scan rates. As shown in Fig. $8 \mathrm{a}$ and $\mathrm{b}$, it can be clearly seen that $\mathrm{NiSe}_{2} / \mathrm{RGO}$ NPs and $\mathrm{NiSe}_{2}$ NPs electrodes both showed excellent reversible responses. Meanwhile, their reduction and oxidation peak currents increase gradually and regularly with the scan rate increasing from 10 to $100 \mathrm{~mA} \mathrm{~cm}{ }^{-2}$. Fig. 8c illustrates the Ox-1 and Red-1 peak current densities of the $\mathrm{NiSe}_{2} / \mathrm{RGO}$ NPs and $\mathrm{NiSe}_{2}$ NPs CEs versus the square root of the scan rate. Both CEs exhibit nearly linear relationships for all the lines. Furthermore, the Ox- 1 and Red- 1 peak current densities of the $\mathrm{NiSe}_{2} / \mathrm{RGO}$ NPS at different scan rates are all higher than those of the $\mathrm{NiSe}_{2} \mathrm{NPs}$, further proving the enhanced electrocatalytic activity of the dispersed $\mathrm{NiSe}_{2}$ nanoparticles on graphene. ${ }^{36,47}$

The long-term stability of the $\mathrm{NiSe}_{2} / \mathrm{RGO}$ NPs and $\mathrm{NiSe}_{2} \mathrm{NPs}$ CEs was evaluated by repeatedly recording 20-cycle CV curves at a scan rate of $25 \mathrm{mV} \mathrm{s}^{-1}$, as shown in Fig. $8 \mathrm{~d}$. It is apparent that the $\mathrm{NiSe}_{2}$ NPs CE showed an obvious change in peak current density and $E_{\mathrm{pp}}$ after 20 cycles of scanning, which is owing to the aggregation during the electrocatalytic reaction. After being combined with graphene, the $\mathrm{NiSe}_{2} / \mathrm{RGO}$ NPs CE exhibited excellent long-term stability and negligible change took place, revealing that dispersed distribution on graphene effectively improved the chemical stability of $\mathrm{NiSe}_{2} \mathrm{NPs}$. The enhanced electrocatalytic performance and long-term stability demonstrated that $\mathrm{NiSe}_{2} / \mathrm{RGO}$ NPs are a good candidate electrocatalyst to replace expensive Pt materials for DSSCs. 


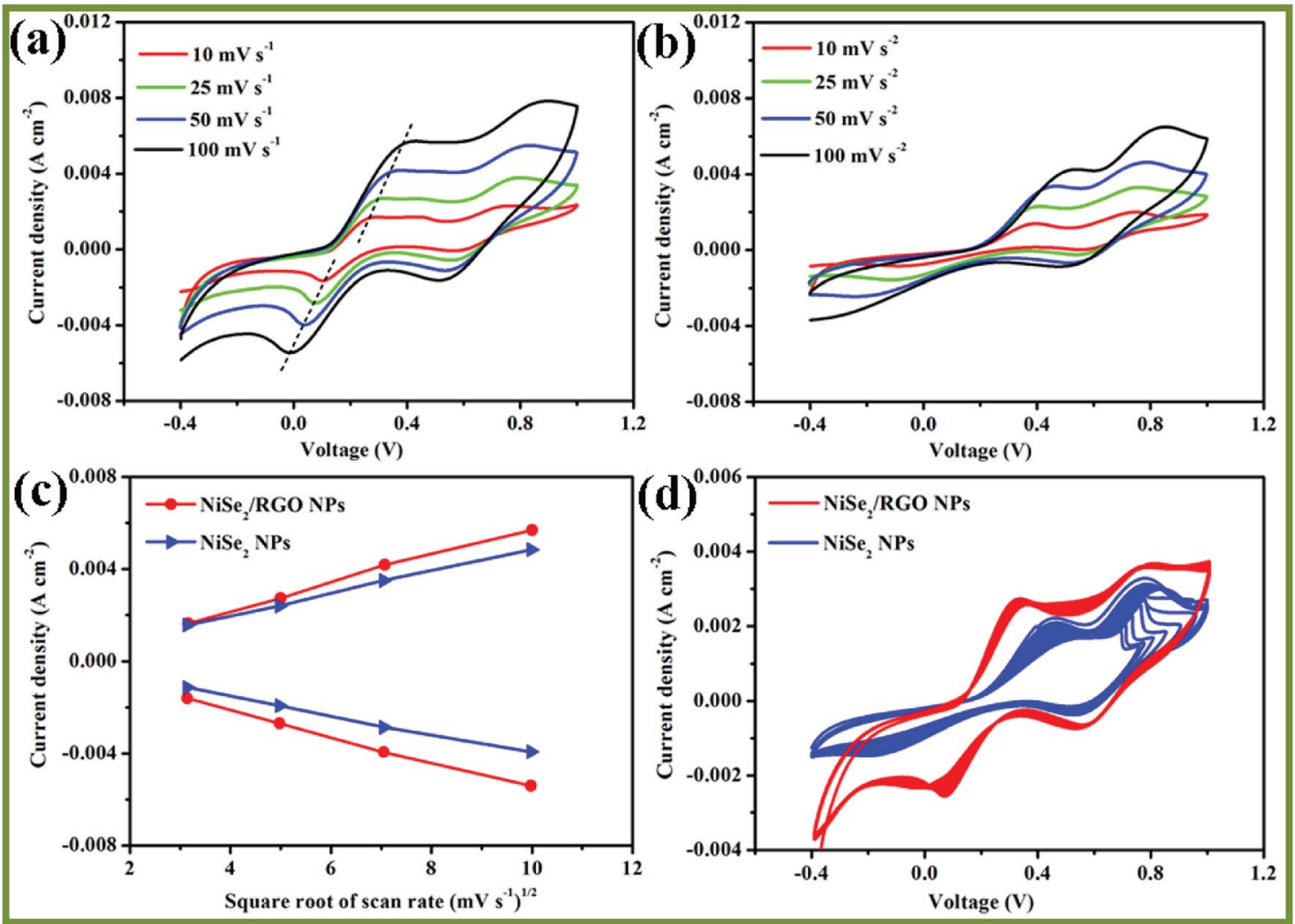

Fig. 8 Cyclic voltammograms of $\mathrm{NiSe}_{2} / \mathrm{RGO} \mathrm{NPs} \mathrm{(a),} \mathrm{NiSe}_{2} \mathrm{NPs}(\mathrm{b})$ at different scan rates. Relationship between redox current densities and the square root of the scan rates (c). 20 consecutive cyclic voltammograms of $\mathrm{NiSe}_{2} / \mathrm{RGO}$ NPs and NiSe $\mathrm{NPs}_{2}$ (d).

\section{Conclusion}

In summary, in this work we successfully fabricated nickel diselenide electrocatalysts with enhanced electrocatalytic performance through a simple and cost-effective method. With the assistance of graphene, $\mathrm{NiSe}_{2} / \mathrm{RGO}$ NPs exhibited better chargetransfer ability and catalytic activity in comparison with expensive Pt electrodes. These enhanced electrocatalytic performance of $\mathrm{NiSe}_{2} /$ RGO NPs were well demonstrated via its lower $R_{\mathrm{ct}}$, higher $J_{\mathrm{SC}}, \mathrm{FF}$ and PCE values. We believe that this work will have significant implications for enhancing electrocatalytic performance and the further development of nickel diselenide.

\section{Conflicts of interest}

The authors declare no competing financial interest.

\section{Acknowledgements}

The authors acknowledge the financial support from the National Science Foundation of China (No. 51776219).

\section{References}

1 U. Bach, D. Lupo, P. Comte, J. E. Moser, F. Weissortel, J. Salbeck, H. Spreitzer and M. Grätzel, Nature, 1998, 395, 583-585.
2 H. Chen, F. Ye, W. T. Tang, J. J. He, M. S. Yin, Y. B. Wang, F. X. Xie, E. B. Bi, X. D. Yang, M. Grätzel and L. Y. Han, Nature, 2017, 550, 92-95.

3 A. Shah, P. Torres, R. Tscharner, N. Wyrsch and H. Keppner, Science, 1999, 285, 692-698.

4 A. Yella, H. W. Lee, H. N. Tsao, C. Y. Yi, A. K. Chandiran, M. K. Nazeeruddin, E. W. G. Diau, C. Y. Yeh, S. M. Zakeeruddin and M. Grätzel, Science, 2011, 334, 629634.

5 S. F. Zhang, X. D. Yang, Y. H. Numata and L. Y. Han, Energy Environ. Sci., 2013, 6, 1443-1464.

6 H. Ren, H. Shao, L. Zhang, D. Guo, Q. Jin, R. Yu, L. Wang, Y. Li, Y. Wang, H. Zhao and D. Wang, Adv. Energy Mater., 2015, 5, 1500296.

7 K. Yoo, J. Y. Kim, J. A. Lee, J. S. Kim, D. K. Lee, K. Kim, J. Y. Kim, B. Kim, H. Kim, W. M. Kim, J. H. Kim and M. J. Ko, ACS Nano, 2015, 9, 3760-3771.

8 J. H. Wu, Z. Lan, J. M. Lin, M. L. Huang, Y. F. Huang, L. Q. Fan, G. G. Luo, Y. Lin, Y. M. Xie and Y. L. Wei, Chem. Soc. Rev., 2017, 46, 5975-6023.

9 M. Chen, L. L. Shao, Z. Y. Yuan, Q. S. Jing, K. J. Huang, Z. Y. Huang, X. H. Zhao and G. D. Zou, ACS Appl. Mater. Interfaces, 2017, 9, 17949-17960.

10 S. Huang, J. Zai, D. Ma, Z. Hu, Q. He, M. Wu, D. Chen, Z. Chen and X. Qian, Electrochim. Acta, 2017, 241, 89-97.

11 H. Yuan, Q. Z. Jiao, J. Li, X. F. Liu, H. Y. Yang, Y. Zhao, Q. Wu, D. X. Shi and H. S. Li, J. Power Sources, 2016, 336, 132-142. 
12 S. S. Huang, D. Ma, Z. J. Hu, Q. Q. He, J. T. Zai, D. Y. Chen, H. Sun, Z. W. Chen, Q. Q. Qao, M. H. Wu and X. F. Qian, ACS Appl. Mater. Interfaces, 2017, 9, 27607-27617.

13 F. Du, X. Q. Zuo, Q. Yang, G. Li, Z. L. Ding, M. Z. Wu, Y. Q. Ma and K. R. Zhu, J. Mater. Chem. C, 2016, 4, 10323-10328.

14 F. Du, X. Q. Zuo, Q. Yang, B. Yang, G. Li, H. B. Tang, H. L. Zhang, M. Z. Wu and Y. Q. Ma, Sol. Energy Mater. Sol. Cells, 2016, 149, 9-14.

15 S. N. Yun, A. Hagfeldt and T. L. Ma, Adv. Mater., 2014, 26, 6210-6237.

16 Q. L. Liu, Y. J. Dong, Y. Cao, H. Y. Chen, D. B. Kuang and C. Y. Su, Electrochim. Acta, 2017, 250, 244-250.

17 P. J. Li, Y. G. Zhang, W. J. Fa, X. G. Yang and L. Wang, J. Power Sources, 2017, 360, 232-242.

18 H. Q. Zhou, Y. M. Wang, R. He, F. Yu, J. Y. Sun, F. Wang, Y. C. Lan, Z. F. Ren and S. Chen, Nano Energy, 2016, 20, 29-36.

19 X. D. Cui, Z. Q. Xie and Y. Wang, Nanoscale, 2016, 8, 1198411992.

20 Z. T. Jin, M. R. Zhang, M. Wang, C. Q. Feng and Z. S. Wang, Acc. Chem. Res., 2017, 50, 895-904.

21 C. Yu, X. Meng, X. Song, S. Liang, Q. Dong, G. Wang, C. Hao, X. Yang, T. Ma, P. M. Ajayan and J. Qiu, Carbon, 2016, 100, 474-483.

22 F. Wang, Y. Li, T. A. Shifa, K. Liu, F. Wang, Z. Wang, P. Xu, Q. Wang and J. He, Angew. Chem., Int. Ed., 2016, 55, 69196924.

23 F. Gong, X. Xu, Z. Q. Li, G. Zhou and Z. S. Wang, Chem. Commun., 2013, 49, 1437-1439.

24 B. Yu, X. Wang, F. Qi, B. Zheng, J. He, J. Lin, W. Zhang, Y. Li and Y. Chen, ACS Appl. Mater. Interfaces, 2017, 9, 7154-7159.

25 H. Zhou, F. Yu, Y. Liu, J. Sun, Z. Zhu, R. He, J. Bao, W. A. Goddard, S. Chen and Z. Ren, Energy Environ. Sci., 2017, 10, 1487-1492.

26 X. Meng, C. Yu, B. Lu, J. Yang and J. Qiu, Nano Energy, 2016, 22, 59-69.

27 C. Y. Su, Y. P. Xu, W. J. Zhang, J. W. Zhao, X. H. Tang, C. H. Tsai and L. J. Li, Chem. Mater., 2009, 21, 5674-5680.

28 X. Zhang, Y. X. Yang, S. Q. Guo, F. Z. Hu and L. Liu, ACS Appl. Mater. Interfaces, 2015, 7, 8457-8464.

29 Z. Zhuang, Q. Peng, J. Zhuang, X. Wang and Y. Li, Chem. -Eur. J., 2005, 12, 211-217.
30 B. Yang, X. Q. Zuo, P. Chen, L. Zhou, X. Yang, H. J. Zhang, G. Li, M. Z. Wu, Y. Q. Ma, S. W. Jin and X. S. Chen, ACS Appl. Mater. Interfaces, 2015, 7, 137-143.

31 B. Wang, X. Wang, B. Zheng, B. Yu, F. Qi, W. Zhang, Y. Li and Y. Chen, Electrochem. Commun., 2017, 83, 51-55.

32 K. Ahmad, A. Mohammad and S. M. Mobin, Electrochim. Acta, 2017, 252, 549-557.

33 X. Meng, C. Yu, X. Song, Z. Liu, B. Lu, C. Hao and J. Qiu, J. Mater. Chem. A, 2017, 5, 2280-2287.

34 M. Chen, G. Zhao, L. L. Shao, Z. Y. Yuan, Q. S. Jing, K. J. Huang, Z. Y. Huang, X. H. Zhao and G. D. Zou, Chem. Mater., 2017, 29, 9680-9694.

35 H. Yuan, Q. Jiao, J. Liu, X. Liu, Y. Li, D. Shi, Q. Wu, Y. Zhao and H. Li, Carbon, 2017, 122, 381-388.

36 X. Zhang, S. Q. Guo, M. M. Zhen, G. D. Gao and L. Liu, J. Electrochem. Soc., 2015, 162, H774-H779.

37 S. Q. Guo, L. C. Wang, C. G. Zhang, G. C. Qi, B. C. Gu, L. Liu and Z. H. Yuan, Nanoscale, 2017, 9, 6837-6845.

38 L. Li, Q. Lu, J. Y. Xiao, J. W. Li, H. Mi, R. Y. Duan, J. B. Li, W. M. Zhang, X. W. Li, S. Liu, K. Yang, M. X. Wu and Y. C. Zhang, J. Power Sources, 2017, 363, 9-15.

39 J. Balamurugan, S. G. Peera, M. Guo, T. T. Nguyen, N. H. Kim and J. H. Lee, J. Mater. Chem. A, 2017, 5, 17896-17908.

40 H. M. Li, X. Qian, C. L. Zhu, X. C. Jiang, L. Shao and L. X. Hou, J. Mater. Chem. A, 2017, 5, 4513-4526.

41 Y. H. Wu, B. Zhou, C. Yang, X. Zhou and W. H. Zhang, Chem. Commun., 2017, 53, 5445-5448.

42 W. Yang, X. Xu, Y. Gao, Z. Li, C. Li, W. Wang, Y. Chen, G. Ning, L. Zhang, F. Yang, S. Chen, A. Wang, J. Kong and Y. Li, Nanoscale, 2016, 8, 13059-13066.

43 X. Meng, C. Yu, X. Song, J. Iocozzia, J. Hong, M. Rager, H. Jin, S. Wang, L. Huang, J. Qiu and Z. Lin, Angew. Chem., Int. Ed., 2018, 57, 4682-4686.

44 X. Meng, C. Yu, X. Song, Y. Liu, S. Liang, Z. Liu, C. Hao and J. Qiu, Adv. Energy Mater., 2015, 5, 1500180.

45 X. H. Miao, K. Pan, G. F. Wang, Y. P. Liao, L. Wang, W. Zhou, B. J. Jiang, Q. J. Pan and G. H. Tian, Chem.-Eur. J., 2014, 20, 474-482.

46 Y. Lou, W. J. Zhao, C. G. Li, H. Huang, T. Y. Bai, C. L. Chen, C. Liang, Z. Shi, D. Zhang, X. B. Chen and S. H. Feng, ACS Appl. Mater. Interfaces, 2017, 9, 18046-18053.

47 X. Qian, H. M. Li, L. Shao, X. C. Jiang and L. X. Hou, ACS Appl. Mater. Interfaces, 2016, 8, 29486-29495. 